\title{
"Fruto da terra e do trabalho humano": paleoterritórios e diversidade da Mata Atlântica no Sudeste brasileiro ${ }^{1}$
}

\section{"Fruit of the earth and work of human hands" paleo-territories and the diversity in Southeastern Brazilian Rain Forest}

\author{
Rogério Ribeiro de Oliveira*
}

\begin{abstract}
Resumo
Este trabalho se ocupa da origem da dimensão humana presente na biodiversidade de remanescentes de Mata Atlântica do Sudeste brasileiro. Estes remanescentes são em grande parte constituídos por florestas secundárias em função de usos históricos. Um ponto ligado à composição destes fragmentos é a existência de paleoterritórios de populações passadas, que os utilizaram como áreas de sobrevivência. Um paleoterritório consiste na espacialização das resultantes ecológicas decorrentes do uso dos ecossistemas por populações passadas (ou por atividades econômicas) na busca de suas condições de existência. O estudo considerou três formas de paleoterritórios ligados à: a) produção de alimentos; b) produção de energia e c) circulação de pessoas no século XIX ou anteriormente. A cultura material e a dimensão cultural das paisagens, explicitada no legado cultural e ecológico destes paleoterritórios, contribui para ampliar a compreensão de processos ecológicos hoje presentes, atuando também como um documento da forma de vida de populações passadas.
\end{abstract}

Palavras-chave: florestas secundárias, populações tradicionais, cultura material, estrutura florestal.

\begin{abstract}
This paper deals with the origins of human existence found throughout Atlantic Forest biodiversity remnants in southeastern Brazil. Due to historical uses, these remnants are largely exhibited in present day via secondary forests. The existence of paleo territories, and the former people who used them as survival areas, is evidenced by the composition of these fragments. A paleo territory is the spatial distribution of ecological resources showing
\end{abstract}

\footnotetext{
*Doutor em Geografia. Professor Departamento de Geografia e Meio Ambiente da PUC-Rio. E-mail: rro@ puc-rio.br.

${ }^{1}$ Este artigo foi produzido como uma das atividades do projeto "As delimitações espaciais sobre a pesquisa em história ambiental”, financiado pelo CNPq - Chamada Universal 14/2012.
} 
conditions of existence, resultant from traditional population ecosystem use for economic activities. The study considered three forms of paleo territories linked to: a) food production; b) energy production and c) the circulation of individuals up to and including the nineteenth century. The material vestiges and cultural dimension of landscapes explain the environmental legacy of these paleo territories and help broaden modern understanding of ecological processes, all while documenting the way of life of previous generations.

Key words: Atlantic Rain Forest, traditional populations, material culture, forest structure.

\section{Introdução}

As paisagens são impregnadas de passado. São como que "heranças das sucessivas relações entre homem e natureza", podendo ser vistas tanto como um produto da coevolução das sociedades humanas e do meio natu$\mathrm{ral}^{2}$, quanto a expressão territorial do metabolismo que uma dada sociedade mantém com o sistema natural que a sustenta ${ }^{3}$. Se, por um lado, a paisagem representa simultaneamente a marca e a matriz de processos naturais e sociais, por outro, encontra-se em "permanente construção e reconstrução ao longo do tempo". ${ }^{4}$ Este estado de construção e desconstrução feito por populações presentes e passadas é mediado pelas condições ambientais. Estes usos históricos representaram, portanto, uma significativa transformação de muitos biomas tropicais, principalmente no que se refere à geração de extensas áreas de florestas secundárias. Por outro lado, estas populações deixaram muito pouco em termos de documentação escrita acerca da história da formação da paisagem. Roderick Nash, um dos primeiros autores a utilizar o termo História Ambiental no final da década de 1960, sugeriu que a paisagem fosse interpretada como um documento histórico. ${ }^{5}$

Para a compreensão dos processos de transformação da paisagem na escala da existência humana, importa a consideração de dois de seus pilares:

\footnotetext{
${ }^{2}$ NAVEH, Z. \& LIEBERMAN, A. Landscape ecology: theory and application. Springer-Verlag, New York. 1994. ${ }^{3}$ TELLO, E.; CUSSÓ, X. \& GARRABOU, R. Energy Balance and Land Use: the Making of an Agrarian Landscape from the Vantage Point of Social Metabolism (the Catalan Vallès County in 1860/1870). In: AGNOLETTI, M., (ed.) The Conservation of Cultural Landscapes, Wallingford (Oxfordshire, UK): CAB International, 2006.

${ }_{4}^{4}$ PÁDUA, J. A. As bases teóricas da história ambiental. Estudos Avançados, v. 24, n. 68, p. 81-101, 2010.

${ }^{5}$ WORSTER, D. Para fazer História Ambiental. Estudos Históricos, v. 4, n. 8, p. 198-215, 1981.
} 
a cultura e o território. A cultura, neste contexto, diz respeito às formas de apreensão de recursos naturais por parte das sociedades ao longo do tempo. Já o território, posto que polissêmico, comporta múltiplas dimensões: a simbólica, a jurídica, a territorial, etc. Apesar de sua etimologia ${ }^{6}$ evocar um controle físico ou um exercício de poder, os territórios são também exercidos e apropriados pelo seu uso, cuja percepção confere ao ser humano o sentido de pertencimento, onde se desenvolve sua cultura local. Assim, a reconstrução da história da atividade humana sobre o espaço geográfico é assentada sobre os territórios, manifestados em diferentes escalas, tanto espaciais como temporais. Ao longo da história foram se estabelecendo cadeias de usos do espaço. Com o passar do tempo, estes territórios se sobrepõem, formando uma realidade singular, prenhe de efeitos sinergéticos.

O território é estabelecido sobre uma paisagem. Entre os seus diversos conceitos, um deles a considera como uma estrutura espacial que resulta da interação entre os processos naturais e as atividades humanas. As paisagens são dinâmicas, elas mudam conforme os sistemas socioeconômicos e biofísicos e evoluem em tempos variados. São intrinsecamente culturais, portanto, refletem a história social e econômica de uma região, incluindo a atividade econômica e a sua organização espacial, padrões de ocupação, a demografia, a mobilidade e os fluxos migratórios.

Já o ecossistema integra o componente biótico e abiótico de um dado espaço e consiste em um tipo particular de sistema construído a partir de redes de fluxos de energia e matéria. Em termos de tamanho, constitui uma delimitação teórica em cima destas redes. Nele interagem organismos e fatores ambientais, organizados em níveis tróficos e necessariamente ligados através de fluxos de energia e matéria. Trata-se, portanto, de uma estrutura multiescalar e apriorística - depende da escala determinada pelo observador. Assim, como um modelo teórico, o ecossistema tem a sua existência concreta apenas manifestada na paisagem, ou seja, imerso em uma torrente de processos, sejam eles evolutivos, estocásticos, biológicos ou sociais. Assim, nesta perspectiva, o ecossistema está para a paisagem assim como ela está para o território. A paisagem tem sua concretude e o seu vetor de transformação a partir dos territórios que nela se estabeleceram ao longo do tempo.

\footnotetext{
${ }^{6}$ Existem duas acepções etimológicas para território: 1) do latim territorium "terra em torno de uma cidade ou de um domínio"; 2) derivada de terrere "assustar", assim territorium significaria "um lugar a partir do qual as pessoas estão alertadas". (Online Etimology Dictionary. London: Douglas Harper. 2001. Disponível em: http://www.etymonline.com/index.php" Acesso em 14/08/2015).
} 
Ao longo da história, a ocupação humana sobre o planeta foi moldando a paisagem e por ela sendo moldada. Um número crescente de pesquisas em ecologia histórica vem identificando legados biológicos em paisagens domesticadas de longa duração. Florestas que foram manejadas no passado podem apresentar diferentes legados no presente em função das suas diferentes histórias de ocupação, muitas vezes pré-colonial. A composição florística encontrada em florestas maduras pode ser consequência de um mosaico de sistemas de manejo. Estas marcas podem ser identificadas no presente por métodos ecológicos, históricos e etnobotânicos. ${ }^{7}$ Importa considerar que estes sistemas híbridos são onipresentes nos remanescentes florestais e entender a sua origem significa compreender o presente.

o trecho do título ("fruto da terra e do trabalho humano") é parte integrante do cânon (a parte central da missa católica) do Missal Romano e é pronunciado pelo sacerdote antes da transubstanciação do pão e do vinho em corpo e sangue de Cristo. Manter a aparência mudando a essência é algo que igualmente se aplica ao estudo dos remanescentes florestais do Sudeste brasileiro. Dentro deste quadro conceitual, a proposta da presente contribuição é examinar na paisagem as marcas do passado deixadas pelo uso de ecossistemas pelos seus territórios e formas de uso. Usaremos três exemplos que se passaram em épocas diversas na história da ocupação humana da Mata Atlântica do Sudeste.

\section{Paisagem e trabalho}

As paisagens são impregnadas de trabalho. Uma parte muito considerável do que chamamos "paisagem natural" constitui um produto da agência e do trabalho humano e, ao ser admirada como natural, importa muito se suprimimos dela o trabalho ou se o reconhecemos ${ }^{8}$. Não obstante, as interações de populações e ocupações pretéritas com diversos ecossistemas vêm sendo negligenciadas, não somente no discurso ambiental, como também em estudos de ecologia. Decodificar a paisagem constitui (re)conhecer o trabalho humano nela impresso. Estes usos, ordenados pelas intencionalidades, necessidades e adaptações das populações passadas que estabeleceram seus antigos territórios e uma vez refeitos pelas dinâmicas naturais, são parte substancial daquilo que hoje chamamos de "natureza".

\footnotetext{
${ }^{7}$ LINS J. et al. Pre-Columbian Floristic Legacies in Modern Homegardens of Central Amazonia. PLoS ONE, v. 10, n.6 p. 1-10, 2015.

${ }^{8}$ WILLIAMS, R. Cultura e Materialismo. Trad. André Glaser. São Paulo: Editora UNESP, 2011.
} 
Este mosaico de usos na paisagem faz com que os biomas, particularmente a atual Mata Atlântica seja constituída, em grande parte, por paleoterritórios utilizados pelas populações que a habitaram. A cada uso superposto no tempo e no espaço, podem ser esperadas resultantes ecológicas distintas, de acordo com a transformação imposta por cada território e pela dinâmica natural dos ecossistemas. Ao longo do tempo, a sucessão destes usos deixa marcas, se espacializa e se sobrepõe como paleoterritórios - conceito proposto como uma parte do processo sucessional e definido como a espacialização das resultantes ecológicas decorrentes do uso dos ecossistemas por populações passadas (ou por atividades econômicas) na busca de suas condições de existência. ${ }^{9}$ Como estes estão em constante transição social e ecológica, os paleoterritórios constituem um repositório de histórias profundas acerca da relação sociedade/natureza. Constituem, portanto, um enfoque e um caminho analítico para o historiador ambiental entender as dinâmicas da transformação da paisagem e da sociedade. Na medida em que esta última se torna mais complexa, a paisagem resultante é mais híbrida devido à relação entre o mundo humano e o mundo não-humano.

$O$ viés analítico do paleoterritório pode ser estendido, a rigor, a qualquer espaço onde tenha havido uso no passado. É, por excelência, o campo de trabalho dos arqueólogos, principalmente onde a cultura material se faz intensa. No entanto, quando empregado para o estudo de áreas hoje desabitadas, abre novas perspectivas para os estudos ecológicos. Procurar história onde a vegetação tomou conta - e mais, entender os rumos da sucessão ecológica - pode ser um caminho para a história ambiental e para a ecologia histórica. Esta tarefa se reveste de particular importância ao se constatar que vivemos hoje um processo de intensa transformação da paisagem florestal. A destruição das formações primárias tem criado uma paisagem característica, na qual as matas mais bem preservadas se apresentam como verdadeiras "ilhas" em um "mar" de vegetação secundária, em diferentes estágios sucessionais. ${ }^{10}$ Os 600 milhões de hectares atuais de florestas secundárias existentes nos trópicos favorecem a ideia de que estamos vivendo em plena "era da vegetação secundária". ${ }^{11}$

\footnotetext{
${ }^{9}$ OLIVEIRA, R. R. Environmental History, Traditional Populations, and Paleo-territories in the Brazilian Atlantic Coastal Forest. Global Environment, v. I, p. 176-191, 2008.

${ }^{10} \mathrm{UHL}, \mathrm{C}$. Factors controlling succession after slash and burn agriculture in Amazonia. Journal of Ecology, v. 75, p. 377-407. 1987.

${ }^{11}$ GÓMEZ-POMPA, A. \& VÁSQUEZ-YANES, C. Studies on secondary succession of tropical lowlands: the life cycle of secondary species. Proceedings of First International Congress of Ecology. The Hague. p. 336-342. 1974.
} 
Em termos de tamanho e gênese, os paleoterritórios podem apresentar escalas e origens diversas. Um paleoterritório pode ser o resultado da forma de uso de uma única cultura agindo em uma mesma área por um curto tempo ou, pelo contrário, muitas culturas agindo em um vasto espaço por muito tempo.

Assim, podemos entender que parte do ofício do historiador ambiental é a identificação e o reconhecimento dos paleoterritórios que se existiram em uma determinada área ao longo do tempo. A sua compreensão pode desempenhar um papel crucial no entendimento do caráter híbrido dos atuais ecossistemas. Conceitos atuais em ecologia como ecossistemas cosmopolitas ou ecossistemas emergentes, ${ }^{12}$ que têm sido bastante empregados, têm sua gênese no estudo da resultante de usos pretéritos. Geralmente estes usos ou cadeias de usos podem dar origem a alterações não intencionais, com reflexos na biodiversidade dos ecossistemas, como veremos a seguir. Estes usos pretéritos transformam as florestas em sistemas híbridos por excelência.

\section{Paleoterritórios na Mata Atlântica: alguns exemplos}

Para a compreensão das mudanças na composição dos ecossistemas importa conhecer as alterações - sejam elas naturais ou antropogênicas a que estiveram submetidos. Evidentemente não se pode tomar como um dado confiável que as atividades humanas e os eventos ecológicos estejam significativamente documentados e disponíveis em registros históricos escritos. Ainda que para os grandes complexos socioeconômicos se disponha de uma documentação considerável, o mesmo não se aplica às populações tradicionai ${ }^{13}$ que habitaram parte considerável dos remanescentes da Mata Atlântica. A ação destes grupos sobre as florestas foi muito variada, de acordo com as pressões da sociedade envolvente. Veremos a seguir três exemplos de resultantes ecológicas de paleoterritórios.

\footnotetext{
${ }^{12}$ BEINART, B. Bio-invasions, Biodiversity, and Biocultural Diversity: some problems with these concepts for historians. In: MAUCH, C., ROBIN, L. (eds.) The Edges of Environmental History. Honouring Jane Carruthers. Munich: RCC Perspectives. p 75-80. 2014.

${ }^{13}$ DIAMOND, J. O mundo até ontem. $O$ que podemos aprender com as sociedades tradicionais. Rio de Janeiro: Ed. Record. 2014. Segundo este autor, o termo sociedade tradicional (transicional ou de pequena escala) diz respeito a sociedades do passado e do presente com baixa densidade populacional que vivem em pequenos grupos de poucas dezenas a poucos milhares de pessoas, subsistindo com a caça e a coleta, a agricultura e transformada, em grau limitado, com as sociedades grandes e ocidentalizadas.
} 
Paleoterritórios ligados à produção de alimento

Muitas áreas utilizadas no passado como áreas de sustento de populações encontram-se hoje recobertas pela Mata Atlântica. Em grande parte, tratavam-se de áreas onde era praticada a roça de coivara.

A Mata Atlântica foi, e em parte ainda é habitada por muitos grupos sociais, hoje denominados genericamente como populações tradicionais, como as comunidades descendentes de etnias indígenas, populações miscigenadas, remanescentes de quilombos ou grupos descendentes de imigração mais recente, como os caiçaras. Uma parte bastante considerável do atual bioma da Mata Atlântica guarda vestígios significativos destes usos pós-coloniais. A histórica relação entre essas populações periféricas à economia central deixou um legado considerável na estrutura, composição e funcionalidade do bioma. Ao contrário destes grupos periféricos, os grandes sistemas socioecológicos (como o do café e o do açúcar) tiveram uma relação muito mais significativa com a erradicação da Mata Atlântica do que com a sua alteração estrutural.

Um ponto em comum faz convergir a quase totalidade destes grupos culturais: a forma como é feita a agricultura. Em função das características ecológicas das florestas tropicais e, em particular da Mata Atlântica, os conhecimentos produzidos por estas populações sofrem uma verdadeira seleção de práticas e o resultado disso é uma convergência entre processos culturais de origem bastante distantes entre si, no que se refere ao tempo ou ao espaço. Esta convergência de técnicas abrange tanto populações pós-coloniais como pré-coloniais (figura 1).

Figura 1 - Abertura de área para a implantação de uma roça de toco na Ilha Grande, Rio de Janeiro.

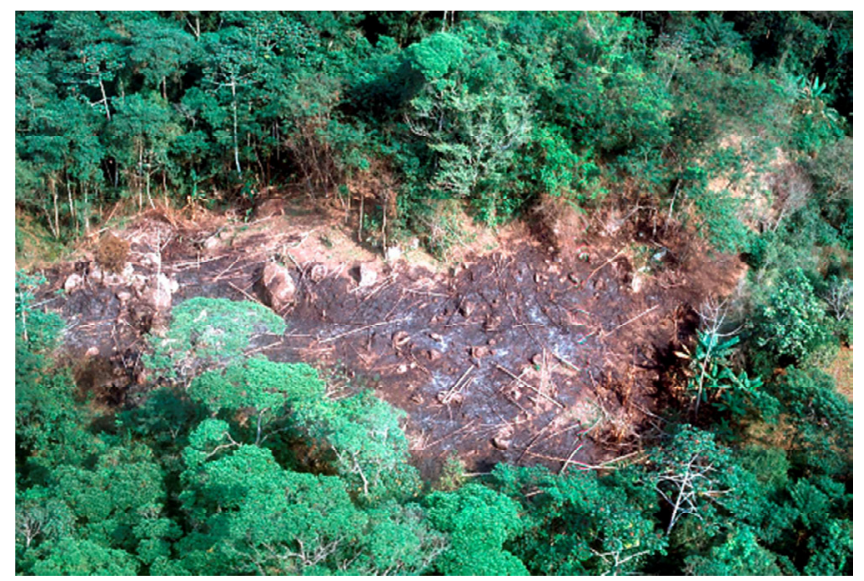


O fogo é uma ferramenta fundamental para este tipo de cultura. Tratase de uma ferramenta barata e adequada aos propósitos da regeneração da floresta, desde que determinadas etapas deste tipo de agricultura sejam seguidos. A essência da agricultura itinerante consiste na abertura de um trato de floresta, sua secagem e posterior incendimento. A fertilização induzida pela queima da floresta permite o uso do solo por um determinado tempo. Após um período de cerca de três anos, a produtividade sofre um decréscimo, sendo então abandonado para um descanso (pousio), em que a floresta secundária coloniza a área. Após um tempo, a capoeira emergente pode ser derrubada e queimada para novo plantio. O pousio é uma prática integrante desta técnica, e consiste em permitir o crescimento de uma capoeira visando a recuperação do solo exaurido pelo cultivo. No entanto as áreas podem ser abandonadas por tempo consideravelmente superior, particularmente quando ocorrem mudanças socioeconômicas na população.

$\mathrm{O}$ uso do capital de nutrientes da vegetação florestal como forma de fertilização dos cultivos consiste na principal característica de um paleoterritório de grande extensão, abrangendo a maioria das áreas remanescentes da Mata Atlântica. Esta abrangência é evidenciada pela frequente presença de fragmentos de carvão nos solos. ${ }^{14}$

A vegetação instalada nas áreas de cultivo após o seu abandono para pousio desenvolve-se não apenas em função da disponibilidade de propágulos disponíveis, mas é também selecionada pelas características do manejo empregado. Da mesma forma, a capacidade de rebrota dos tocos, a resistência dos mesmos à ação do fogo, a dominância de determinadas espécies são fundamentais para a retomada da floresta. Assim, por diversos caminhos, o manejo feito "orienta" a sucessão natural - e consequentemente a biodiversidade da floresta que coloniza o local.

Assim, em relação à composição dos ecossistemas florestais, considera-se que os processos históricos de ocupação do território da Mata Atlântica tenham alterado severamente os padrões de diversidade atual deste bioma. Áreas abandonadas e anteriormente submetidas à tradicional prática de agricultura de coivara mostram, de uma maneira geral, uma redução no número de espécies de porte arbóreo ou arbustivo e uma predominância de espécies pioneiras e secundárias, em detrimento das climáxicas. Ao longo de um gradiente temporal de distintas áreas abandonadas submetidas anteriormente à agricultura de caiçaras na Ilha Grande (Rio de Janeiro), mesmo após

${ }^{14}$ OLIVEIRA, R. R.; SOLÓRZANO, A. Três Hipóteses Ligadas à Dimensão Humana da Biodiversidade da Mata Atlântica. Fronteiras: Sociedade, Tecnologia e Meio Ambiente, v. 3, p. 80-95, 2014. 
50 anos de abandono, o número total de espécies arbóreo-arbustivas é de $47 \%$ de uma área climáxica. ${ }^{15}$ Uma espécie que caracteriza o paleoterritório de roças de caiçaras é o jacatirão (Miconia cinnamomifolia (DC.) Naudin) (figura 2). Trata-se de uma espécie pioneira, que se instala logo após o abandono da roça. No entanto trata-se de uma espécie longeva, podendo chegar a 150 anos de idade. A sua ocorrência sob a forma populações de um mesmo porte pode ser usada não só para detectar o paleoterritório como para datá-lo. ${ }^{16}$

Figura 2 - Caule de jacatirão (Miconia cinnamomifolia) em área usada para cultivos possivelmente no século XIX (Maciço da Pedra Branca, RJ).



A relativa baixa riqueza florística constitui, portanto, uma significativa característica da agricultura de coivara. Os paleoterritórios gerados pelo abandono das roças orientam a sucessão ecológica e, por conseguinte alteram a paisagem que neles se instala. A evolução muito lenta de formações secundárias com uma estrutura e cortejo florístico particulares caracteriza o chamado clímax antrópico ou antropogênico. ${ }^{17}$ Aceitando-se esta definição,

\footnotetext{
${ }^{15}$ OLIVEIRA, R. R. When the shifting agriculture is gone: functionality of Atlantic Coastal Forest in abandoned farming sites. Boletim do Museu Paraense Emílio Goeldi. Ciências Humanas, v. 3, p. 213-226, 2008. ${ }^{16}$ DELAMONICA, P.; LIMA, D. F.; OLIVEIRA, R. R.; MANTOVANI, W. Estrutura e funcionalidade de populações de Miconia cinnamomifolia (DC.) Naud. em florestas secundárias estabelecidas sobre antigas roças caiçaras. Pesquisas. Botânica, São Leopoldo, RS, v. 52, p. 125-142, 2002.

${ }_{17}$ SASTRE, C. Notion de climax em régions néotropicales. Compte rendu des Sceances de la Societé de Biogeographie, v. 58, n.3, p. 117-123,1982.
} 
o estabelecimento de um clímax antrópico parece ser a principal marca na estrutura e composição da vegetação que a atividade agrícola destas populações tradicionais deixou sobre a paisagem florestada e que deve permanecer longo tempo após o término da intervenção do homem sobre o meio. A manifestação florística e estrutural encontrada nestas áreas reflete a provável pressão seletiva exercida pelos sucessivos períodos de pousio e cultivo a que foram submetidas por longo tempo.

Paleoterritórios ligados à produção de energia

Historicamente a lenha sempre acompanhou a trajetória humana como fonte energética de primeira necessidade. A sua transformação em carvão via combustão abafada (os fornos de carvão) possibilita um aumento do poder calórico com uma redução de massa, o que o torna uma fonte de energia que permite ser transportada a distâncias mais longas. 0 poder calorífico do carvão vegetal por unidade do peso é quase três vezes maior do que a lenha. Ao contrário dos combustíveis fósseis, o carvão pode ser produzido localmente e trata-se de uma fonte de energia cujo custo de produção é composto quase exclusivamente do trabalho humano investido nele..$^{18}$

Em numerosos trechos de florestas da América Central e do Sul são encontrados no seu interior vestígios de antigas carvoarias. No Estado do Rio de Janeiro um contingente muito significativo destas carvoarias data de meados do século XIX. Apenas no Maciço da Pedra Branca (localizado na Zona Oeste do Rio de Janeiro), atualmente recobertas por densa floresta atlântica, foram encontrados, até o momento, vestígios (platôs) de 1.044 antigas carvoarias (figura 3). ${ }^{19}$

Com relação à formação do paleoterritório dos carvoeiros no Maciço da Pedra Branca, a paisagem florestal gerada constitui um verdadeiro documento que permite, em alguma medida, entender a forma de exploração de recursos. Muito possivelmente, a fabricação de carvão era um trabalho para escravos alforriados ou pequenos agricultores e não parte integrante do sistema produtivo dos engenhos. Mesmo antes da abolição da escravatura no Brasil em 1888, os escravos foram aos poucos sendo colocados à parte das atividades produtivas. Com a abolição, passaram a constituir um grande contingente de desempregados, sem recursos para a sobrevivência.

\footnotetext{
${ }^{18}$ OLSON, S.D. Firewood and Charcoal in Classical Athens. Hesperia, vol. 60, n. 3, p. 411-420. 1991.

${ }^{19}$ OLIVEIRA, R. R.; FRAGA, J. S. Metabolismo social de uma floresta e de uma cidade: paisagem, carvoeiros e invisibilidade social no Rio de Janeiro dos séculos XIX e XX. GeoPuc , v. 4, p. 1-18, 2012.
} 
Assim, a fabricação do carvão era uma atividade que permitia uma relativa independência, já que a quantidade de insumos utilizada na produção de carvão era mínima. Um machado, um enxadão, um ancinho e fogo era tudo o que se precisava para a sua produção. Apesar do intenso processo de invisibilização social a que os carvoeiros estavam sujeitos, somente no Maciço da Pedra Branca, eles foram responsáveis pela exploração de uma área de mais de 10.000 hectares. Hoje, transformado em um Parque Estadual, sua floresta atlântica tem a estrutura e composição florística em grande parte modificadas por esta atividade do passado. As implicações ecológicas da exploração da lenha para a produção de carvão não resultaram em efeitos ecológicos negativos expressivos. A retomada da floresta nas áreas desmatadas foi significativa. Do total das antigas carvoarias localizadas no Maciço da Pedra Branca, apenas 2,1\% foram encontradas em áreas abertas (capim). As demais $97,9 \%$ das carvoarias encontravam-se no interior da floresta, em estágios diversos de sucessão ecológica.

Figura 3 - Platô de uma antiga carvoaria do século XIX no Maciço da Pedra Branca, RJ.

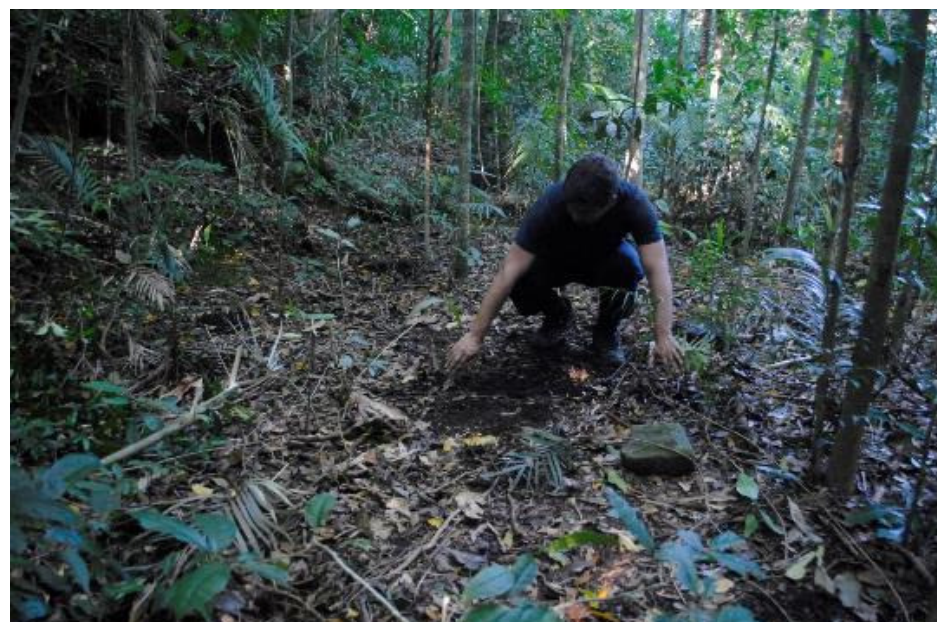

Com relação à biodiversidade da paisagem presente nas áreas onde ocorreu a exploração de carvão, um levantamento feito nas áreas de exploração de carvão inventariou 350 espécies de árvores e arbustos em uma área de um hectare.$^{20} \mathrm{O}$ paleoterritório dos carvoeiros encontra-se, portanto, em

\footnotetext{
${ }^{20}$ FREIRE, J.M. Composição florística e estrutura do estrato arbóreo de uma floresta urbana no Maciço da Pedra Branca - RJ. 2010. 124 f. Tese (Doutorado em Ciências Ambientais e Florestais). Instituto de Florestas, Universidade Federal Rural do Rio de Janeiro, 2010.
} 
estágio avançado de regeneração. Na mesma área foi encontrada uma proporção de espécies em estágio inicial de sucessão (pioneiras e secundárias iniciais) de $37 \%$, sendo os demais $63 \%$ pertencentes ao grupo das secundárias tardias e climáxicas. 0 que se pôde observar é que, apesar da composição da floresta ter sido comprometida em parte pela derrubada das árvores, sua estrutura e funcionalidade foram significativamente recuperadas. A consequência ecológica mais significativa foi possivelmente a redução da diversidade, mas não de biomassa.

Com o processo da sucessão ecológica a floresta se recuperou, no entanto, apresentando marcas, que se manifestam tanto na estrutura como na composição da paisagem florestal. Algumas destas marcas são ligadas diretamente à cultura material, a começar com as 1.044 carvoarias mapeadas no Maciço. Outro ponto de interesse são as ruínas utilizadas pelos carvoeiros. $\mathrm{Na}$ mesma pesquisa foram igualmente mapeados 81 baldrames (fundações rasas feitas de pedras empilhadas sem rejunte) de antigas moradias de carvoeiros. A figura 4 apresenta a localização do acervo das 1.044 carvoarias.

Figura 4 - Localização de carvoarias no Maciço da Pedra Branca (zona oeste do Rio de Janeiro).

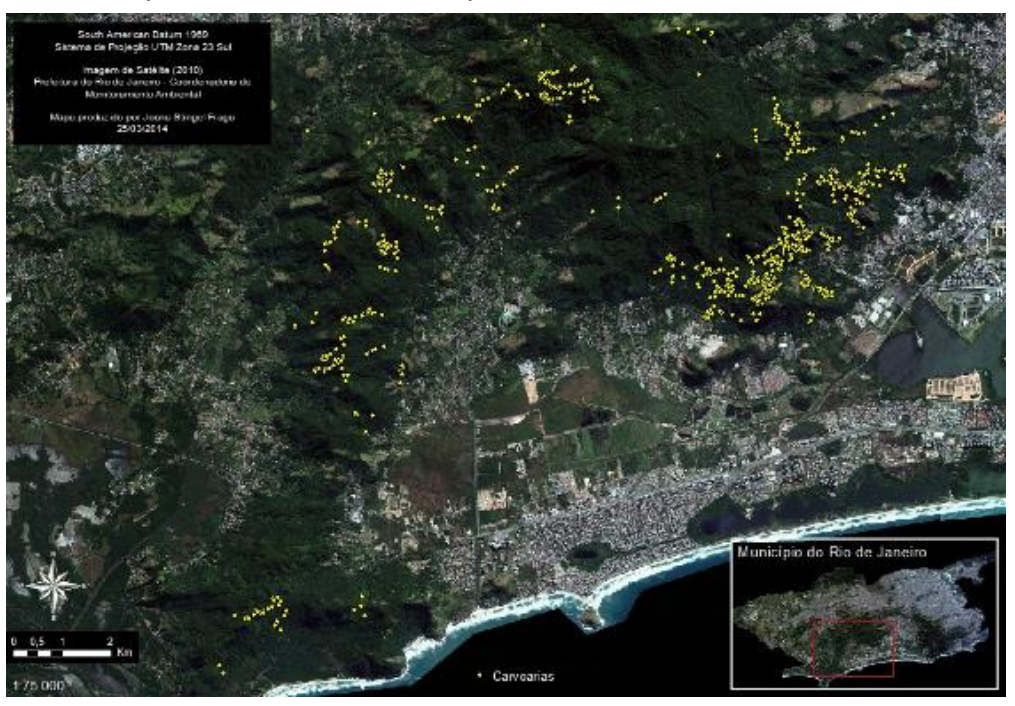

Dentre as inúmeras alterações que esta atividade do passado causou na composição e na estrutura da vegetação, destaca-se a modificação das comunidades faunísticas e florísticas. A estrutura de um ecossistema é predominantemente explicada pela variação no ambiente físico, assim 
como a estrutura atual é fortemente influenciada por processos históricos. ${ }^{21}$ São muitos os caminhos para se entender as respostas do ecossistema a distintos regimes de perturbação. Por exemplo, o tamanho das populações, a composição de espécies, assim como a presença e abundância de árvores mortas, podem ser utilizados como elementos diagnósticos. Tamanhos uniformes nas árvores de dossel frequentemente indicam a existência pretérita de um evento em larga escala, como a retirada de lenha ou a ocorrência de severos distúrbios climáticos.

A atual distribuição de uma das espécies mais comuns na floresta, a carrapeta (Guarea guidonia (L.) Sleumer), é emblemática. Trata-se de uma espécie frequente em formações secundárias iniciais e tardias do Maciço da Pedra Branca. Um estudo feito em áreas de floresta do Maciço da Pedra Branca $^{22}$, promoveu o inventário de todos os exemplares de carrapeta em uma área total de 1,35 ha. $22 \mathrm{Na}$ área de uma carvoaria (cuja floresta ao redor Branca é presentemente dominada por esta espécie) foi um estudo antracológico (a identificação botânica do carvão). A análise dos fragmentos de carvão feita em área onde hoje a carrapeta é dominante sugere que a atividade carvoeira, que existiu no local há mais de 150 anos, provocou grande redução na diversidade das outras espécies e aumento substancial da densidade desta espécie. Esta análise identificou 113 tipos anatômicos, ${ }^{23}$ os quais apontam para um número de espécies possivelmente ainda mais elevado, já que em virtude das características da anatomia do lenho, cada táxon, geralmente identificado ao nível de espécie ou família, pode conter mais de uma espécie. Esta riqueza de espécies é bastante superior ao que existe atualmente - apenas 43 espécies em levantamento fitossociológico recente feito na área. Assim, Guarea guidonia pode ser apontada como uma espécie indicadora do histórico de intervenção do homem sobre o ambiente florestado.

\section{Paleoterritórios de circulação}

A circulação humana nos espaços continentais do país sempre foi algo complexo, ainda mais com a variabilidade no que se refere ao trinômio dis-

\footnotetext{
${ }^{21}$ KESSLER, M. \& KLUGE, J. Diversity and endemism in tropical montane forests - from patterns to processes. In: GRADSTEIN, S.R.; HOMEIER, J. \& GANSERT, D. (eds.) The Tropical Mountain Forest - Patterns and processes in a Biodiversity Hotspot. Göttingen: Centre for Biodiversity and Ecology. Biodiversity and Ecology Series, V. 2, p. 35-50, 2008.

${ }^{22}$ OLIVEIRA, R. R.; SOLÓRZANO, A.; SALES, G. P. S.; Oliveira, M.B.D ; Sheel-Ybert, R. Ecologia histórica de populações da carrapeta (Guarea guidonia (L.) Sleumer) em florestas de encosta do Rio de Janeiro. Pesquisas. Botânica, v. 64, p. 323-339, 2013.

${ }^{23}$ BEAUCLAIR, M.D.O. Produção de carvão e mudanças na paisagem do Maciço da Pedra Branca, Rio de Janeiro, RJ. Dissertação (Mestrado em Geografia) - Pontifícia Universidade Católica do Rio de Janeiro. 2010.
} 
tância/clima/relevo. Na América do Sul existem muitas referências aos chamados peabirus - antigos caminhos utilizados pelos indígenas sul-americanos desde muito antes do descobrimento pelos europeus, ligando o litoral ao interior do continente. Um deles teria cerca de 4 mil quilômetros e ligaria o oceano Atlântico ao Pacífico do litoral catarinense, paranaense e paulista à costa do Peru e Chile. ${ }^{24}$

No período colonial tornam-se conhecidas as chamadas Estradas Reais. A par de um caráter oficial e de uma exclusividade de utilização, apresentavam um sólido vínculo com a mineração. Na ligação da região aurífera e diamantina de Minas Gerais destacavam-se dois caminhos: o Caminho Velho, que ia de Paraty a Vila Rica (atual Ouro Preto) e o Caminho Novo, do fundo da baía de Guanabara até encontrar o Caminho Velho em Ouro Branco, então arraial de Vila Rica, atual Ouro Preto, com uma extensão total de $1.400 \mathrm{~km} .{ }^{25}$

O botânico Auguste de Saint-Hilaire transitou por alguns destes caminhos no Estado de São Paulo em 1822, observando, já na época, a heterogeneidade da paisagem:

"Esta alternativa de cafezais e matas virgens, roças de milho, capoeiras, vales e montanhas, esses ranchos, essas vendas, essas pequenas habitações rodeadas das choças dos negros e as caravanas que vão e vêm, dão aos aspectos da região grande variedade". ${ }^{26}$

No entanto, estes caminhos estavam longe de se constituírem rotas únicas que ligavam dois pontos. Uma série de caminhos paralelos, ramais, atalhos e diferentes trajetos de subidas de serra encheram as serranias do Sudeste brasileiro de inúmeras rotas. Se nas partes planas quase nada restou de vestígios destas rotas, na Serra do Mar e na Serra da Mantiqueira, assim como nos maciços costeiros do Rio de Janeiro, Minas Gerais e São Paulo, se podem encontrar numerosos destes caminhos. Estes se encontram presentemente em grande parte soterrados, descaracterizados e inteiramente recobertos pela vegetação florestal. Em trechos de maior declividade o talude artificial é evidente, mas em trechos mais planos é difícil o resgate da trajetória original do caminho. Alguns são de extensão reduzida (algo como 10 $15 \mathrm{~km}$, como alguns localizados no Maciço da Pedra Branca, RJ), outros, con-

\footnotetext{
${ }^{24}$ BOND, R. História do Caminho de Peabiru - Descobertas e segredos da rota indígena que ligava o Atlântico ao Pacífico. Rio de Janeiro: Editora Aimberê. 2010.

${ }^{25}$ SANTOS, M. Estradas Reais. Introdução ao estudo dos caminhos do ouro. Belo Horizonte: Editora Estrada Real, 2001.

${ }^{26}$ SAINT-HILAIRE, A. Segunda viagem do Rio de Janeiro a Minas Gerais e a São Paulo. Belo Horizonte: Editora Itatiaia, 1976.
} 
sideravelmente mais longos - com até $80 \mathrm{~km}$ de extensão, como o que liga o alto da Serra da Bocaina (SP) ao litoral, em Mambucaba (Angra dos Reis, RJ) (figura 5). Sobre este veremos a seguir algumas características específicas.

Figura 5 - Área de antigas fazendas de café em São José do Barreiro (SP). Ao fundo a Serra da Bocaina, local onde passava o antigo caminho de ligação para Mambucaba, no litoral de Angra dos Reis (RJ).

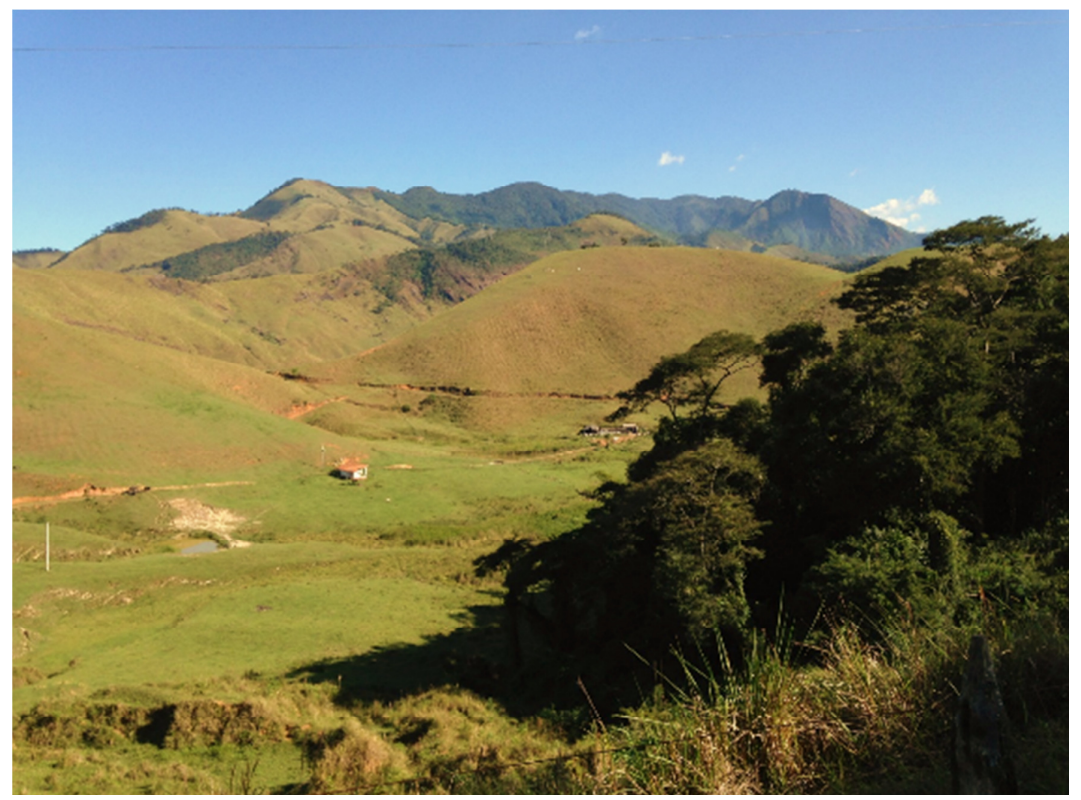

Trata-se de um caminho (com vários ramais e entroncamentos) que segue pelo domínio da Floresta Ombrófila Densa Submontana e Montana, em estágio avançado de regeneração. Com cerca de $80 \mathrm{~km}$ de extensão liga, em seu trecho principal, o atual município de São José do Barreiro (SP) ao litoral fluminense. Este caminho ia margeando o rio Mambucaba, seguindo até a Serra Geral e do Frade, onde bifurcava-se para Silveiras, São José do Barreiro e Rezende. Sua largura média é de 2,5 m e é calçado em sua maior parte por rochas, algumas com cerca de $1 \mathrm{~m}^{2}$ (figura 6). Dada a irregularidade do piso pode-se descartar a possibilidade do trânsito de carros de bois. 0 seu uso era feito por muares em sua maior parte. Existem relatos de numerosas tropas de burros transportando o café do vale do Rio Paraíba para São Paulo. ${ }^{27}$ Como a ligação ferroviária em São José do Barreiro em 1892, este

${ }^{27}$ LAMEGO, A. R. O Homem e a Serra. Rio de Janeiro: Ed. IBGE - Conselho Nacional de Geografia. 1963. 
caminho não mais foi utilizado para drenar a produção de café da região. Até o presente se encontra um tráfego regular de mulas transportando bananas do curso superior do rio Mambucaba até o litoral.

Figura 6 - Aspectos do leito do caminho que liga São José do Barreiro (SP) a Mambucaba (Angra dos Reis, RJ).
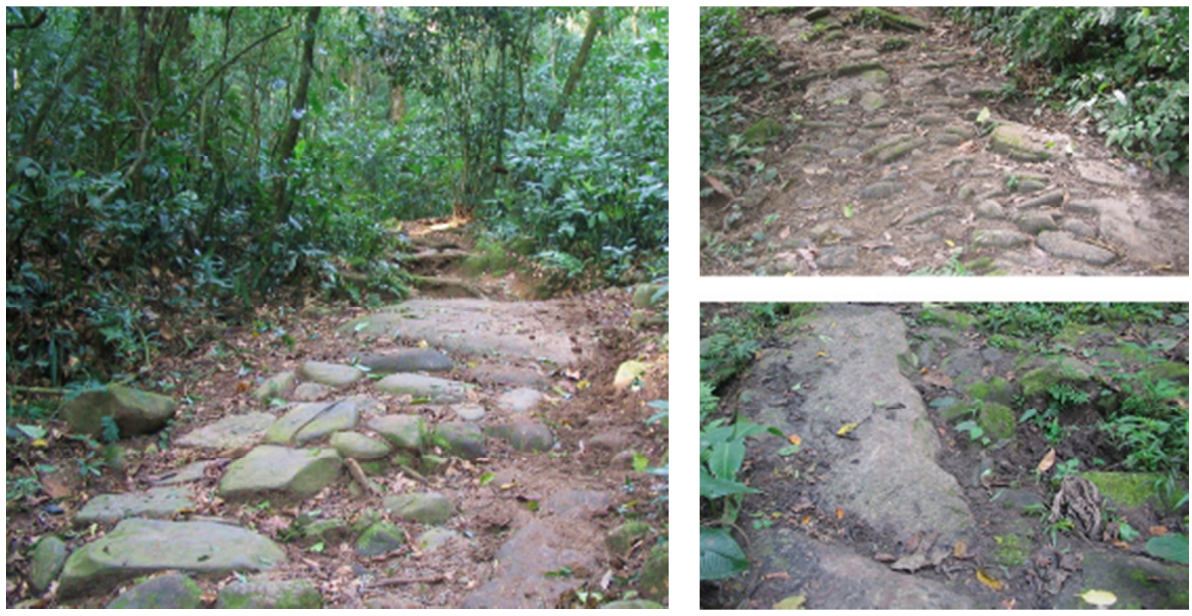

Um ponto de destaque é que estes caminhos não constituíam uma simples passagem por florestas e serras desabitadas. Eles foram vetores de uma ocupação lateral, em parte ligada ao uso da estrada. Esta ocupação, posto que incipiente, foi responsável por modificações na estrutura das florestas remanescentes e que persistem até hoje. Muito possivelmente a provisão de alimentos, tanto para homens quanto para os muares, foi o motor desta ocupação.

Do alto da Mantiqueira, descia-se as vertentes do Rio Verde, já em território de Minas Gerais, passando-se pelos pinheirais, cujos frutos sustentavam os mineiros. Em fins do século XVII, já eram comuns as roças de milho, feijão e outros gêneros alimentícios que, junto com animais domésticos, eram vendidos por preços exorbitantes. ${ }^{28}$

É de se destacar, portanto, que esse caminho, mais que um simples ponto de ligação entre o interior e o litoral, serviu também como polo

\footnotetext{
${ }^{28}$ COSTA, A.G. As estradas reais para as minas na cartografia histórica do Brasil. In: CALAES, G.D. \& FERREIRA, G.E. (Eds.) A Estrada Real e a Transferência da Corte Portuguesa. Rio de Janeiro: CETEM / MCT / CNPq / CYTED, 2009. p. 7-20.
} 
irradiador de exploração e uso da terra ao longo de todo o seu trajeto. Embora os relatos em sua grande maioria sejam ligados à tradição oral, numerosos e significativos vestígios comprovam a hipótese de que toda a floresta localizada nas margens desse caminho foi palco de um uso regular a partir do século XVIII por populações que habitavam estes sertões ${ }^{29}$. Ao longo de praticamente todo este caminho, a Mata Atlântica ali localizada é constituída por florestas secundárias em estágio avançado de regeneração. Vestígios de carvão nos primeiros $5 \mathrm{~cm}$ do solo evidenciam também o uso pretérito destas terras como roças para o auto abastecimento de populações que exploravam a área como roças de coivara, baseada no sistema derrubada - queima - plantio - pousio.

Outro ponto bastante significativo destes caminhos é relativo à necessidade de pastagens para as tropas que nele circulavam. Uma das características mais marcantes ligadas à utilização direta da biomassa de florestas tropicais é o fato de ela mesma ser muito pouco palatável tanto pelo ser humano quanto pela fauna que não evoluiu com o ecossistema como os bovídeos e equídeos (trazidos pelo colonizador). A sua fitomassa é formada por grande número de compostos secundários, sendo os mais frequentes os taninos, compostos terpenóides, alcalóides e glicosídeos. ${ }^{30}$ A pressão da herbivoria levou, ao longo da evolução, à formação de defesas químicas e mecânicas, como tentativa de afastar ou intoxicar os herbívoros. Altas concentrações de taninos e características esclerófilas podem constituir barreiras para a alimentação de herbívoros não especialistas. ${ }^{31}$ Este é exatamente o caso dos herbívoros trazidos pelo colonizador: cavalos e mulas. Assim, o deslocamento ao longo da Serra do Mar somente seria possível se, a trechos regulares, existissem pastagens com espécies de gramíneas palatáveis pelas mulas. Saint-Hilaire, em 1822 assim se referiu ao movimento de tropas e à necessidade de pouso, pasto e milho:

A fazenda onde parei fica situada, exatamente, na raiz da serra e como as tropas que passam pela montanha aí fazem parada forçosamente, há grande movimento de mulas [...] e o proprietário vale-se da necessidade que todos têm de recorrer a ele, e o milho se vende, mais caro que em outro lugar. ${ }^{32}$

\footnotetext{
${ }^{29}$ Estes vestígios foram estudados e levantados em trabalhos de campo feitos pelo autor e colaboradores ao longo deste caminho. 0 mesmo se encontra no domínio da Floresta Ombrófila Densa Submontana, na bacia hidrográfica do Rio Mambucaba (RJ).

${ }^{30}$ COLEY, P. D.; BARONE, J. A. Herbivory and plant defenses in tropical forests. Annual Review of Ecology and Systematics, v. 27, p. 305-335, 1996.

${ }^{31}$ SILVA, J. O. et al. Esclerofilia, taninos e insetos herbívoros associados a Copaifera lagsdorffii Desf. (Fabaceae: Caesalpinioideae) em área de transição Cerrado-Caatinga no Brasil. Ecol. austral, v.19, n. 3, p. 47-63. 2009.

${ }^{32}$ SAINT-HILAIRE, A. Viagem pela província de São Paulo. Belo Horizonte: Ed. Itatiaia. 1976. p. 47.
} 
A figura 7 apresenta uma pastagem atualmente não utilizada, mas com evidências de ter sido utilizada no passado como pouso de muares para a travessia São José do Barreiro - Mambucaba. Geralmente estas pastagens eram de uma espécie africana, o capim-gordura (Melinis minutiflora P. Beauv.), altamente palatável pelos muares..$^{33}$

Figura 7 - Pastagem circunscrita por floresta no caminho São José do Barreiro - Mambucaba. Na parte superior se observa o talude de um trecho do mesmo.

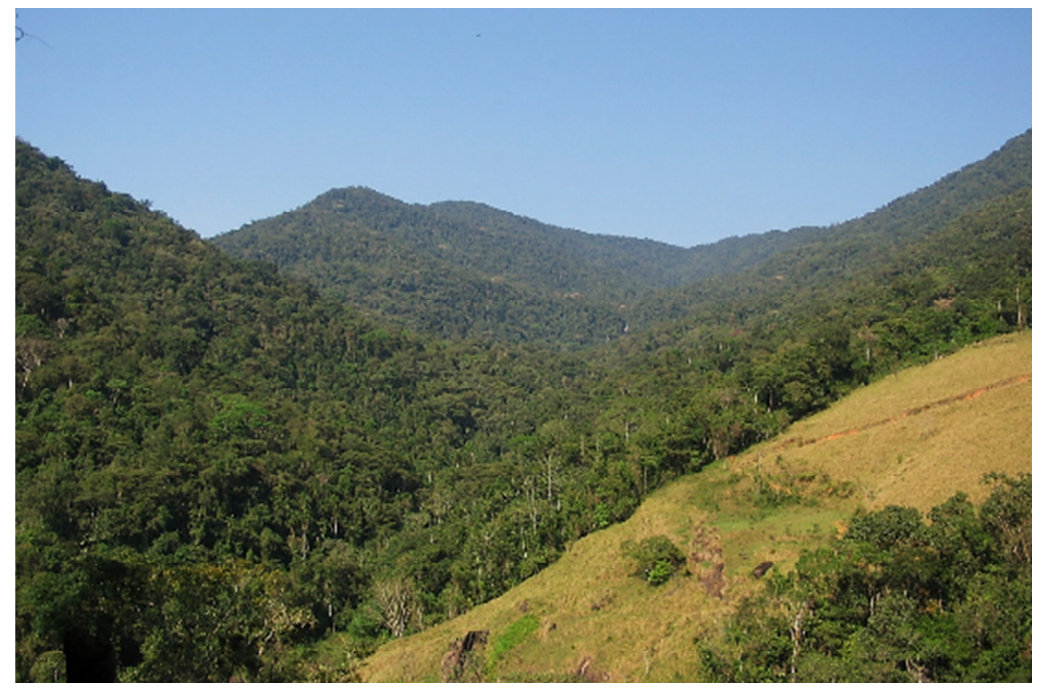

A biodiversidade local guarda marcas desta presença histórica em dois de seus atributos: na estrutura e na composição. Na metade inferior da estrada dois levantamentos fitossociológicos ${ }^{34}$ feitos no interior da mata que engloba o caminho indicaram uma área basal ${ }^{35}$ de 50,2 e 75,7 $\mathrm{m}^{2} / \mathrm{ha}$, valores compatíveis com florestas secundárias avançadas. No total foram amostradas 53 espécies de árvores ou arbustos. Chama a atenção, no entanto, o fato de que foram amostradas também espécies exóticas no interior da floresta, indicando o uso anterior da mesma (figura 8).

\footnotetext{
${ }^{33}$ SILVA, S. D. ; MATEUS, R. A. ; BRAZ, V. S. ; PEIXOTO, J. C. . A fronteira gado e a Melinis minutiflora P. Beauv. (POACEAE): a história ambiental e as paisagens campestres no Cerrado Goiano no século XIX. Sustentabilidade em Debate, v. 6, p. 17-32, 2015.

${ }^{34}$ SVORC, R. C. P. F.; OLIVEIRA, R. R. Uma dimensão cultural da paisagem: biogeografia e história ambiental das figueiras centenárias da Mata Atlântica. GEOUSP: espaço e tempo, v. 32, p. 124, 2012.

${ }^{35} \mathrm{~A}$ área basal representa o somatório da área seção dos troncos com diâmetro $\geq 5,0 \mathrm{~cm}$ em um hectare. É obtida por meio de amostragens em áreas reduzidas (parcelas). A área basal tem relação direta com a biomassa de uma floresta.
} 
Figura 8 - Exemplares de cacau (Theobroma cacao L.) e limão-galego (Citrus aurantifolia (Christem.) Swingle encontrados ao longo do caminho Mambucaba-São José do Barreiro.
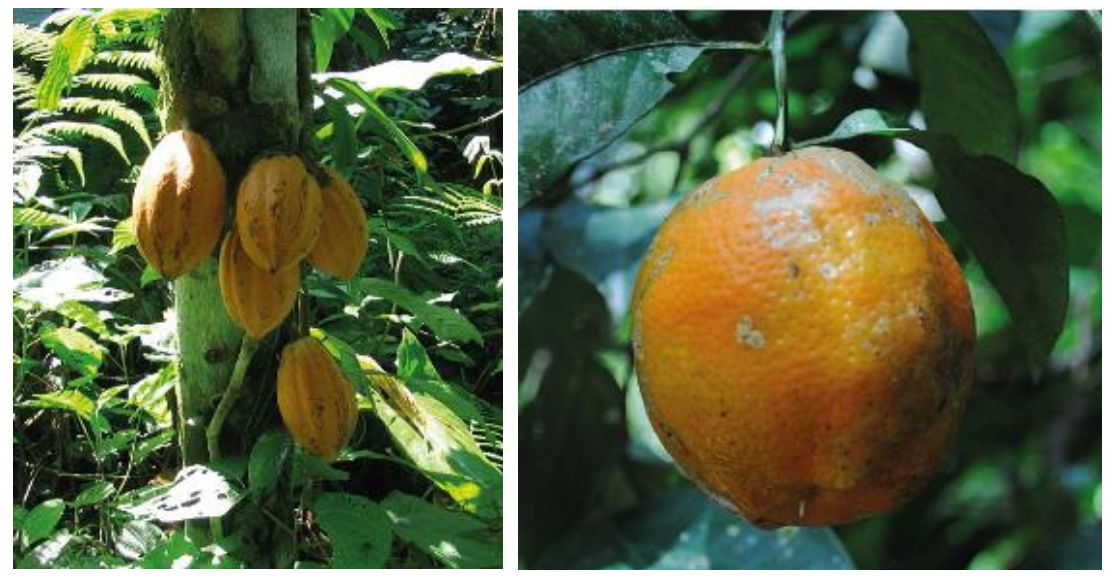

\section{Aspectos comuns aos três paleoterritórios: marcas na vegetação e paisagem não material}

Finalmente, deve-se destacar a presença de aspectos comuns aos três paleoterritórios estudados. Um deles é a frequente ocorrência de troncos bifurcados encontrados no interior das formações secundárias estudadas (figura 9). Em termos morfológicos, o que caracteriza um exemplar de porte arbóreo é a presença de um tronco único apresentando a divisão em galhos somente após um fuste relativamente retilíneo. No entanto, nestas áreas são frequentemente encontrados troncos de espécies arbóreas que apresentam bifurcação próximo ao nível do solo. Tratam-se de exemplares que foram derrubados no passado. $O$ ponto de crescimento do rebroto é exatamente a altura (cerca de 50-70 cm), onde foi utilizado o machado para a sua derrubada no passado. Em decorrência da perda da dominância da gema apical, ocorre o perfilhamento que produz troncos bifurcados. ${ }^{36} \mathrm{~A}$ presença destes exemplares no interior nas florestas estudadas nos três exemplos de paleoterritórios representa uma indicação análoga à da cultura material. Muitas vezes onde vestígios arqueológicos são inexistentes, esta alteração na forma de crescimento de árvores pode representar a única fonte de informação histórica.

\footnotetext{
${ }^{36}$ A remoção artificial da gema apical remove a fonte de dominância apical, estimulando o desenvolvimento das gemas axilares, por promover o aumento de citocininas nas gemas laterais (MARQUES, V.B. Profundidade de plantio e dominância apical na estaquia de pitaia vermelha. Semina: Ciências Agrárias, v. 33, n. 6, p. 2091-2098 2012).
} 
Figura 9 - Troncos perfilhados indicando corte das árvores no passado. 0 local de rebroto dos troncos localiza-se na altura do corte do machado, entre 30 e $60 \mathrm{~cm}$ do nível do solo.
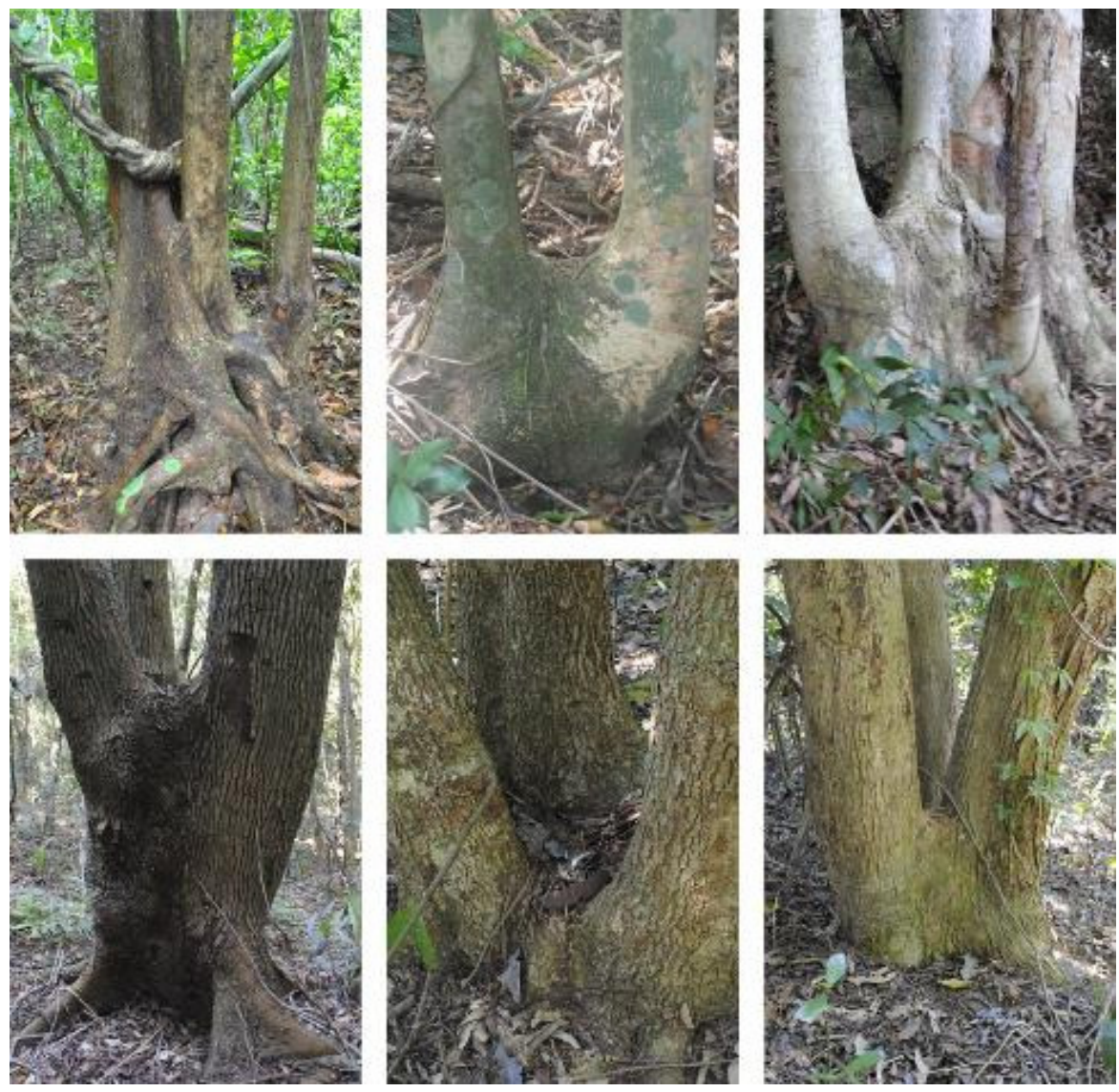

As marcas da presença humana na paisagem são de naturezas muito diversas, podendo assumir contornos tanto materiais como imateriais. Este é o caso das figueiras centenárias da Mata Atlântica, que passaremos a examinar. ${ }^{37}$

Na maioria das florestas secundárias do Sudeste Brasileiro, é notável a presença de figueiras de grande porte do gênero Ficus (Moraceae), preservadas da derrubada por razões culturais por populações tradicionais (figura 10).

${ }^{37}$ SVORC; OLIVEIRA, op, cit. 
Estes grandes exemplares também são conspícuos nos três paleoterritórios estudados.

Figura 10 - Exemplar de uma figueira nativa (Ficus glabra) em meio a um paleoterritório de carvoeiros no Parque Estadual da Pedra Branca (RJ).

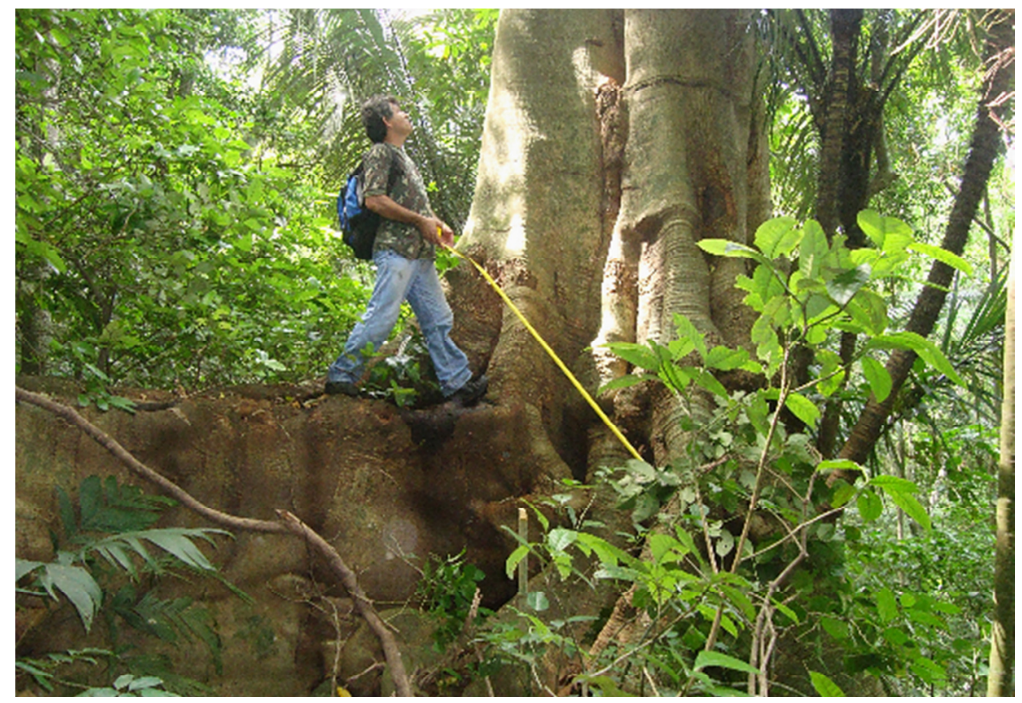

Este tabu é ancorado tanto na tradição judaico-cristã quanto na afro-brasileira. Embora no Brasil existam cerca de 100 espécies de figueiras nativas ${ }^{38}$, o gênero Ficus se destaca, tanto pelo aspecto alimentar (representado fundamentalmente por Ficus carica (o figo comestível, uma espécie exótica), quanto pela histórica tradição cultural, presente em muitas partes do mundo. Na costa da África, o iroko é considerado uma árvore sagrada pelo candomblé. ${ }^{39} \mathrm{Na}$ tradição afrodescendente brasileira as figueiras ocupam o lugar da espécie africana (Clorophora excelsa) para representar um deus-árvore: o iroko. No Novo Testamento, Jesus seca (e não amaldiçoa como se vê na tradição popular) uma figueira que não dá fruto ${ }^{40}$. Assim, seja pela tradição judaico-cristã ou pela afro-brasileira, esta árvore é portadora de forte simbolismo e, por estes motivos, é preservada do corte por populações

\footnotetext{
${ }^{38}$ CARAUTA, J.P.P. Ficus (Moraceae) no Brasil: Conservação e taxonomia. Albertoa, v. 2, p. 1-365, 1989.

${ }^{39}$ VERGER, P. Ewé: o uso das plantas na sociedade iorubá. São Paulo: Companhia das Letras, 1995.

${ }^{40}$ Evangelho de S. Mateus, Capítulo 21: versículos 18-22.
} 
interioranas quando promovem derrubadas para a implantação de suas roças. Daí a constante presença de exemplares de elevado porte, servindo como testemunho da história local. Constituem verdadeiros marcos na paisagem, e, em função disso, integram a toponímia de numerosos locais (como Mata da Figueira, Grota da Gameleira, etc.). Mesmo em pastagens ou em áreas urbanizadas de diversas capitais brasileiras, frequentemente as árvores de maior porte são figueiras centenárias.

Este traço cultural foi ao longo do tempo deixando marcas materiais na paisagem. Dentre elas destacam-se as alterações na composição, estrutura e funcionalidade dos ecossistemas. A manutenção pelas populações passadas destes exemplares de figueiras ao longo dos ciclos de uso da paisagem traz como resultantes aspectos ecológicos bastante concretos. Estas figueiras representam um recurso significativo para a fauna local, como o papagaio-chauá (Amazona rodocorytha), o tucano (Ramphastos vitellinus ariel), o araçari-poca (Selenidera maculirostris), o macaco bugio (Alouatta fusca) e outros. Um contingente maior de animais, de hábito noturno, também faz uso desse recurso. A presença dessas árvores constitui, portanto, um importante elemento de atratibilidade e sobrevivência da fauna local. Em certa medida a fauna silvestre depende deste tabu para o equilíbrio de suas populações.

O conceito de espécie-chave cultural, uma metáfora do conceito ecológico de espécie-chave, é relevante na questão da preservação das figueiras e em sua relação com a floresta circundante. Este conceito se refere a espécies "cujo impacto na sua comunidade ou ecossistema é grande e de forma desproporcional em relação à sua abundância". ${ }^{41}$ As figueiras centenárias da Mata Atlântica constituem, portanto, verdadeiros marcos culturais. São encontradas na maioria dos remanescentes florestais do sudeste brasileiro, geralmente apresentando porte elevado. Tal fato evoca o aspecto simbólico da paisagem ao se transmudar em paleoterritório, ao expressar crenças, valores e mitos de uma população. Apesar de distintos históricos de ocupação, os motivos da preservação destes exemplares é o mesmo e faz com que este tabu se encontre espalhado por distintas populações tradicionais do sudeste brasileiro.

\section{Conclusão}

Os imponentes exemplares de figueira, presentes nos três paleoterritórios estudados, remetem à recorrente questão do hibridismo que ocorre

${ }^{41}$ POWER, M. Challenges in the quest for keystones. Bioscience, v. 46, n. 8, p. :609-620, 1996. 
nos sistemas florestais. Além dos aspectos relativos à cultura material expressa em aspectos bióticos da paisagem, a dimensão imaterial do paleoterritório, que se traduz em resultantes ecológicas concretas, traz também à tona o largo espectro de ações de manejo dos ecossistemas por parte de populações tradicionais. O caso particular das figueiras centenárias da Mata Atlântica contribui, de maneira clara, para opor "a ideia de natureza como externalidade ao humano". ${ }^{42}$ Assim, ao mesmo tempo em que estas figueiras constituem marcos de um paleoterritório, representam também um verdadeiro semióforo (algo que não possui utilidade, mas representa o invisível no mundo do visível, ou pelo menos uma interpretação, um diálogo que se estabelece entre os dois mundos). ${ }^{43}$ Ou seja, a transmutação do ecossistema em paisagem e esta, em território. Mediada pelo trabalho humano e pelo passado histórico, a paisagem se transubstancia em uma realidade híbrida e única.

Dessa forma, destaca-se a importância de se considerar o contexto social nos quais os diferentes tempos determinam as atuais características das paisagens, milenarmente construídas em cima de paleoterritórios. A coevolução e interdependência na formação destas paisagens culturais e a maneira com que elas se influenciam mutuamente tanto no aspecto simbólico, como no material explicita a existência de uma floresta-cultura, que coexiste sem oposição a uma "floresta-natureza". Assim, a dimensão cultural da paisagem, explicitada no legado cultural e ecológico dos seus paleoterritórios, contribui para ampliar a compreensão do hibridismo da paisagem florestal do Sudeste brasileiro.

Artigo recebido para publicação em 19/10/2015

Artigo aprovado para publicação 03/11/2015

\footnotetext{
${ }^{42}$ REHBEIN, M.O. \& ROSS, J. L.S. Ambiente; urbano; impacto - impacto ambiental urbano: revisões e construções de significados. GEOUSP - Espaço e Tempo, São Paulo, № 27, pp. 95 - 112, 2010.

${ }^{43}$ ARRUDA, G. Monumentos, semióforos e natureza nas fronteiras. In: Gilmar Arruda. (Org.). Natureza, fronteiras e territórios. 2aed.Londrina: Eduel, 2013, v. 1, p. 1-42.
} 